JOSÉ DUARTE NETO

\title{
RIGIDEZ E ESTABILIDADE CONSTITUCIONAL Estudo da Organização Constitucional Brasileira
}

Tese apresentada à Banca Examinadora à Faculdade de Direito da Universidade de São Paulo, como exigência para obtenção do título de DOUTOR em Direito, sob a orientação do Professor Manoel Gonçalves Ferreira Filho

Faculdade de Direito da Universidade de São Paulo

SÃO PAULO

2009 


\section{RESUMO}

A Constituição de 1988 classifica-se como Rígida, porque seu procedimento de transformação é mais solene do que o das demais leis e normas. A despeito dos limites à sua transformação, experimentou amplas e reiteradas emendas, o que a faz instável. Logo, a Estabilidade constitucional é um dos fins perseguidos pela rigidez constitucional, mas com ela não se confunde.

Por Estabilidade entende-se a capacidade de uma Constituição ou de uma organização constitucional de persistir e transformar-se no tempo, preservando suas principais características. A Estabilidade, enquanto categoria foi compreendida de maneira diferente na Antiguidade, na Idade Média e a partir das revoluções liberais.

Deve-se a James Bryce a classificação das Constituições em Rígidas e Flexíveis. Nas primeiras, centros decisórios distintos produzem normas constitucionais e infraconstitucionais; nas segundas, uma única fonte. O autor também cotejou essas Constituições com a concepção de Estabilidade. O passar dos anos obscureceu essa implicação, a recomendar a revisitação de sua obra.

As Constituições Rígidas são dotadas de uma imutabilidade relativa e de uma supremacia formal. Garantidas por um modelo de controle de constitucionalidade e de institutos de superação de crises. A competência reformadora é obstaculizada por limites normativos, o que faz da Mutação Constitucional, em princípio, a expressão de sua atualização.

A história constitucional brasileira é caracterizada por uma sucessão de Constituições, o que denota uma instabilidade, provocada pelos mais diferentes motivos.

A Constituição de 1988 dispõe de adequados limites à alteração formal e de um complexo modelo de controle de constitucionalidade. De outro lado, não lhe impediu diversas emendas. Todavia, ainda não lhe desestruturou a identidade das normas materialmente constitucionais, sendo uma instabilidade de superfície ou aparente. O perigo é que a banalização das reformas produza uma instabilidade de fundo, que comprometa regras materialmente constitucionais. A advertência recomenda que se investigue uma solução.

PALAVRAS CHAVES: Constituição Rígida. Constituição Flexível. Estabilidade Constitucional. Poder Reformador. Limites ao Poder Reformador. 


\begin{abstract}
The Constitution of 1988 is classified as rigid because its procedure for transformation is more solemn than that of other laws and rules. Despite the limits to its transformation, it has repeatedly undergone ample amendment, which makes it unstable. Hence, constitutional stability is one of the ends sought by constitutional rigidity, but must not be confused with it.

Stability is understood as the ability of a Constitution or constitutional organization to endure and transform itself in time, while preserving its primary characteristics. Stability as a category has been understood in different ways in Antiquity, in the Middle Ages, and with the coming of liberal revolutions.

Classifying Constitutions as rigid and flexible is something we owe to James Bryce. In the former, distinct decision-making centers produce constitutional and sub-constitutional rules; in the latter, a single source does. That author has also compared such Constitutions to the conception of stability. The course of time has cast a shadow on that implication, so revisiting his works might be commendable.

Rigid Constitutions are endowed with a relative immutability and a formal supremacy, and assured by a framework for controlling constitutionality, and by doctrines for overcoming crises. Reformative jurisdiction has the hurdles of regulatory limits, making Constitutional Mutation, in principle, the expression of their updating.

Brazilian constitutional history is characterized by a succession of Constitutions, belying an instability caused by a wide variety of reasons.

The Constitution of 1988 is provided with suitable limits to formal change, and with a complex framework for controlling constitutionality. This, on the other hand, has not prevented its various amendments. However, it has not yet taken apart the identify of materially constitutional rules, as such instability is only superficial or apparent. The danger lies in the triteness of reforms leading to an in-depth stability that compromises materially constitutional rules. This warning commends looking into a solution.
\end{abstract}

KEY WORDS: Rigid Constitution. Flexible Constitution. Stability. Amendment. Limits to Amendment. 


\section{RESUMÉ}

La Constitution de 1988 est classée comme rigide, étant donné que son procédé de transformation est plus solennel que celui des autres lois et normes. En dépit des limites à sa transformation, elle a éprouvé des révisions amples et réitérées, ce qui la rend instable. Par conséquent, la stabilité constitutionnelle est l’un des buts poursuivis par la rigidité constitutionnelle, toutefois, elle ne se confond pas avec celle-ci.

Par stabilité, on comprend la capacité d’une Constitution ou d’une organisation constitutionnelle de persister et de se transformer dans le temps, en gardant ses caractéristiques principales. La stabilité en tant que catégorie a été envisagée de manière différente dans l`Antiquité, au Moyen-Âge et depuis les Révolutions libérales.

On doit à James Bryce la classification des Constitutions en rigides et souples. En ce qui concerne les premières, ce sont des centres décisoires distincts qui produisent les normes constitutionnelles et infra-constitutionnelles, quant aux secondes, elles sont issues d`une seule source. L`auteur a également comparé ces Constitutions avec la conception de stabilité. Avec le temps, cette implication a été obscurcie, il faudrait donc revisiter son oeuvre.

Les Constitutions rigides sont dotées d’une immutabilité relative et d’une suprématie formelle et sont garanties par un modèle de contrôle de constitutionnalité et d`instituts de surpassement de crises. La compétence réformatrice est obviée par des limites normatives, ce qui fait de la Mutation Constitutionnelle, en principe, l'expression de son actualisation. L`histoire constitutionnelle brésilienne est caractérisée par une succession de Constitutions, ce qui dénote une instabilité provoquée par les motifs les plus divers. La Constitution de 1988 dispose de limites adéquates à la modification formelle et d`un modèle complexe de contrôle de constitutionnalité. Par contre, cela n`a pas empêché plusieurs révisions. Néanmoins, l`identité des normes matériellement constitutionnelles n`a pas encore été déstructurée car il s`agit d`une instabilité de surface ou apparente. Le danger, c`est que la banalisation des réformes produise une instabilité de fond qui compromette les règles matériellement constitutionnelles. Il est conseillé de faire des recherches attentives afin d’y trouver une solution.

MOTS - Clés : Constitution Rigide. Constitution Souple. Stabilité. Révision. Limites normatives à revision. 


\section{INTRODUÇÃO}

Esse trabalho foi idealizado a partir de duas observações. A primeira foi a constatação de que a classificação das Constituições em Rígidas e Flexíveis — vários são os autores que assim dissertam — tem a estabilidade por critério de discrime (dos entes classificados). A segunda, que a despeito da Constituição de 1988 ser rígida, não atende ao critério do discrime, pois é constantemente reformada. Em princípio é instável. A partir dessas observações - firmadas em um caso prático - foram erigidas algumas questões: Qual o significado de Estabilidade Constitucional? Qual o sentido de Constituição Rígida? Qual a relação entre Estabilidade e Constituição Rígida? Qual a implicação com seus mais distintos aspectos: normativos, políticos e sociológicos?

As respostas oferecidas a essas primeiras questões exigiram o tratamento da Estabilidade como categoria autônoma, ainda que não desvinculada da concepção de Constituição Rígida. Antes, Howard Lee Mcbain - Ruggles Professor de Direito Constitucional da Universidade de Colúmbia - sugerira o mesmo em uma obra publicada em 1939: The Living Constitution. A obra contou com diversas críticas, que acentuavam a confusão de uma categoria normativa com uma sociológica. Estabilidade. Realmente, Rigidez e Estabilidade são categorias díspares, razão pela qual mais se recomenda a sua investigação em separado.

Essa foi proposta desenvolvida aqui.

A procura pelo sentido de Estabilidade recomendou uma revisitação do pensamento Antigo, Medieval e Moderno, que empregou o Constitucionalismo como instrumento de análise. Muito embora o Constitucionalismo tenha um conteúdo semântico inconfundível - doutrina ou conjunto de doutrina sobre a limitação do poder — nada impede o seu uso como meio de acesso a institutos e obras, que diretamente ou indiretamente, conectaram-se com a Estabilidade. Por isso, foi tido como alavanca epistemológica, o que permitiu a apreensão dos diferentes significados de Estabilidade na Antigüidade, na Idade Média e a partir das Revoluções Liberais.

Em um segundo momento, a obra de James Bryce - A Comunidade Americana e Constituciones Flexibles y Constituciones Rígidas - foi relida. Esse foi o autor que primeiramente estabeleceu a diferença entre Constituições Rígidas e Flexíveis. Constatou-se que ao diferenciar a Constituição Flexível inglesa da Constituição Rígida americana, contrastava-as com a Estabilidade. Elaborou juízos sobre em que aspectos uma 
e outra eram Estáveis. Mas em nenhum momento considerou Rigidez e Estabilidade como “identidades”. Todavia, a sutileza de seu pensamento foi obscurecida ou esquecida pela doutrina produzida a partir de então. Hodiernamente, Constituição Rígida é um conceito jurídico-formal neutro: consiste naquela que dispõe de um procedimento solene de transformação, quando comparado com o rito das normas infraconstitucionais. A Rigidez do procedimento confia-lhe supremacia formal, que por sua vez é garantida pelo Controle de Constitucionalidade. De outro lado, Estabilidade é um conceito obtido da Ciência Política. Trata-se da capacidade de uma Constituição ou organização constitucional de persistir no tempo, transformando-se conforme as exigências sociais e políticas, sem perder suas características essenciais. Há uma Estabilidade de ordem formal e material. Esses dois conceitos - Rigidez e Estabilidade - devem ser utilizados na solução de problemas distintos no âmbito do Direito.

Resolvida a questão conceptual, exigiu-se o enfrentamento da classificação consolidada na doutrina, que agrupa as Constituições em Imutáveis, Fixas, Rígidas, Flexíveis e Semi-Rígidas. Nesse capítulo - com o estudo da obra de Kelsen, Schmitt e Lassalle - foram retomados conceitos clássicos de maneira a fornecer subsídio metodológico para os diferentes aspectos do tema.

O terceiro capítulo foi dedicado ao estudo em particular das Constituições Rígidas. Apesar de a doutrina não explorar em profundidade sua relação com a de Estabilidade, consistem no modelo de constitucionalização do Pós-Guerra. A concepção normativa de Constituição - como regra de Direito, vinculativa do Estado e de comportamentos e submetida ao controle judicial — é resultado de pouco mais de dez lustros. Para esse significado confluíram tradições distintas: a tradição americana, européia revolucionária, européia monárquica e européia democrática do período entre Guerras. Foi, ainda, imprescindível retomar os principais aspectos normativos da Constituição Rígida: a) supremacia constitucional; b) a imutabilidade relativa e a conseqüente previsão de limites normativos; c) os instrumentos de garantia da supremacia constitucional em períodos de normalidade e de exceção.

Com esses ganhos teóricos, no quarto capítulo foi possível investigar a organização constitucional brasileira e a sucessão de Constituições. Analisou-se a estrutura normativa de cada uma delas, em especial quanto aos limites normativos de sua alteração. Uma vez encerrada a análise formal, investigou-se as causas e as razões subjacentes das diferentes rupturas. 
O último capítulo foi dedicado à Constituição de 1988. Foi dividido em diversas seções que tiveram por assuntos: a) origens históricas da Constituição de 1988; b) aspectos formais e sua efetividade: limites ao Poder Reformador e controle de constitucionalidade; c) características das Emendas à Constituição e natureza da instabilidade normativa; d) causas da instabilidade da Constituição de 1988; e) conseqüências da Constituição de 1988; g) proposta de supressão da instabilidade.

Todo o esforço empreendido - que não se cingiu a análise exclusiva de textos normativos - tem a clara intenção de servir ao debate sobre a instabilidade da Constituição de 1988 e fornecer subsídios para superação dessa crise. É erigido sobre a conclusão de que a reforma persistente prejudica a eficácia da opção constituinte, enfraquece o sentimento de grandeza da Constituição e compromete ou coloca em risco a função constitucional de limitar o poder e garantir direitos e garantias fundamentais. 


\section{CONCLUSÕES}

Nenhum trabalho científico é fechado sobre si. A despeito de suas conclusões serem um ponto de chegada, é importante que também possibilitem um recomeço. Nascido e construído sob e sobre o debate, o trabalho científico deve estimular a discussão. Por essa razão, as observações sobre a estabilidade e Constituição Rígida não são definitivas. Sob a vigência da Constituição de 1988, em especial, deixaram aspectos e questões inconclusas. Melhor que assim aconteça, sendo esse o elo para o debate futuro. À guisa de pesquisa futura, como sugestão, impende ainda investigar a relação entre Estabilidade e Constituição Rígida de um lado e governabilidade de outro. Quais os aspectos da Governabilidade que podem ser absorvidos pelo texto de uma Constituição Rígida, qual dimensão deve ser deixada ao âmbito das regras infraconstitucionais? Qual a relação entre Governabilidade e Estabilidade ou Governabilidade e Instabilidade constitucional? São, entre outras, questões a serem resolvidas. Espera-se que as observações a seguir estimulem o debate:

1. Tópicos do Constitucionalismo e Estabilidade.

1.1 As Constituições Rígidas são criações do Constitucionalismo Moderno. A Antigüidade não as conheceu. Foram firmadas para conferir estabilidade e permanência às normas constitucionais. De qualquer forma, Rigidez e Estabilidade são categorias distintas, e como tal, devem ser tratadas.

1.2 A Ciência Jurídica não produziu um estudo monográfico, sistemático e consistente sobre a estabilidade. O empréstimo que dela se faz é da Ciência Política. Entretanto, mesmo na Ciência Política não existe um conceito exclusivo, mas, vários, construídos sobre critérios distintos como a abertura ou fechamento do sistema, o maior ou menor desenvolvimento social de um povo, a relação de congruência entre governantes e governados, a eficácia da decisão tomada.

1.3 Como Rigidez e Estabilidade são categorias autônomas — ainda que se impliquem - imprescindível também que sejam distintamente investigados os seguintes entes: Constituição Rígida, Constituição Flexível, Estabilidade e Instabilidade Constitucional.

1.4 A Estabilidade foi compreendida distintamente nos diversos momentos históricos. A investigação dos seus diversos aspectos é possível de ser feita por meio do 
Constitucionalismo enquanto corpo de doutrinas firmado no tempo e no espaço, com extensa carga valorativa e cujo objeto é a organização e limitação do poder político.

1.5 A despeito de o Constitucionalismo dispor de um núcleo semântico incontroverso, que é a limitação do poder, nada impede que dele se utilize enquanto instrumento epistemológico. Compreenda-se por isso o seu emprego como meio para a análise de elementos acessórios, ou seja, a estabilidade constitucional.

1.6. Há um Constitucionalismo da Antigüidade, um Constitucionalismo Medieval e um Constitucionalismo das Revoluções Liberais, o que por conseqüência, permite antever concepções e enfoques distintos sobre a estabilidade.

1.7. O Constitucionalismo da Antigüidade Clássica foi erigido sobre um mundo em ruínas: em razão Guerra Civil entre ricos e pobres. O pensamento foi elaborado no sentido de recuperar uma estabilidade perdida existente em tempos antigos.

1.8 O Constitucionalismo Medieval tinha por fundamento uma organização política fragmentada e descentralizada entres entes autônomos que se neutralizavam mutuamente. Os pensadores do período compreenderam a estabilidade enquanto idéia de preservação do equilíbrio da Constituição Mista.

1.9 O Constitucionalismo Moderno tem por pressuposto a ruptura revolucionária. Foi construído a partir das Revoluções Liberais, da ideologia Iluminista e dos valores da Ilustração. Crê na razão enquanto força emancipadora, que se realiza na Revolução e que rompe com organizações políticas e sociais históricas. O projeto revolucionário - a idéia Constituinte - é estabilizado somente a partir da vitória revolucionária: por meio de Constituições escritas e Rígidas.

1.10 O Constitucionalismo Revolucionário tem tradições distintas: inglesa, francesa e americana.

1.11. A tradição revolucionária inglesa recupera a estabilidade — por meio da revolução — de um passado remoto. Para tradição revolucionária inglesa estabilidade é o mesmo que restauração das liberdades antigas.

1.12. A tradição revolucionária francesa erige-se sobre a teoria de Sièyes do Poder Constituinte: os homens investem-se da atribuição de construir sua própria organização constitucional. Nada obstante, a tradição francesa foi marcada por uma persistente reconstrução constitucionalo, ou seja, por uma sucessão de Constituições.

1.13. O Constitucionalismo revolucionário americano assenta-se em um momento fundacional ímpar, de difícil reprodução, o que justifica a proteção do texto da Constituição contra mudanças e transformações bruscas e casuísticas, o que é feito pela 
previsão de limites à reforma e a garantia de sua efetividade pelo controle de constitucionalidade.

2. Constituições Rígidas e Estabilidade

2.1. A classificação das Constituições em Rígidas e Flexíveis é criação do gênio de James Bryce. Essa categoria foi inicialmente esboçada na obra The American Commonwealth, e posteriormente desenvolvida na coletânea de ensaios Studies in History and Jurisprudence, no qual compara a organização constitucional histórica inglesa com a Constituição americana.

2.2. A Constituição Flexível tem sua origem em um passado remoto, é histórica e expressão de sociedades antigas que evoluíram e se adaptaram. Ao reverso de ser débi e frági, dispõe de uma elasticidade para se acomodar a situações distintas. É a Constituição da aristocracia, porque somente o mérito tem capacidade para compreender sua intricada dinâmica.

2.3. As Constituições Rígidas são coevas dos tempos modernos, e têm por fundamento uma nítida separação entre as leis ordinárias, próprias do Parlamento, e as normas constitucionais emanadas de uma fonte distinta. São as Constituições do Regime Democrático e das massas, porque permitem absorver em sua dinâmica um grande contingente humano.

2.4. As Constituições Rígidas — por meio de limites à sua transformação formal - impedem os pequenos desvios, que ocorrem sem percepção nas Constituições Flexíveis. Nas Constituições Rígidas, quando acontecem, são comumente flagrados. As Constituições Flexíveis não os percebem. Em contrapartida, não superam as grandes crises, e rompem-se, diferentemente, nas Constituições Flexíveis há uma solução negociada e pautada que autoriza a transição constitucional.

2.5. Em sua obra James Bryce fazia a devida concatenação entre Estabilidade e as categorias Rigidez e Flexibilidade. O mundo hodierno esqueceu essa relação, demandando que seja recuperada para solução de problemas mais distintos.

2.6. O discurso jurídico brasileiro ainda não desenvolveu uma monografia sobre a estabilidade constitucional.

2.7. As Constituições Rígidas almejam uma estabilidade jurídica, mas nem sempre atingem o fim que perseguem. Há uma estabilidade formal e um estabilidade material. A estabilidade constitucional formal tem por pressuposto uma mesma Constituição e, por isso, um ponto de início, confluência e de fundamento de validade: o Poder Constituinte. A estabilidade constitucional material pressupõe a persistência — ou a 
permanência — de uma “decisão política fundamental” ou da “idéia dominante de Direito”.

2.8. Segundo a estabilidade as Constituições podem ser classificadas em Imutáveis, Fixas, Rígidas, Flexíveis e Semi-Rígidas. A primeira categoria não é de utilidade, porque não existe e nunca existiu uma Constituição Imutável. A segunda é uma falsa categoria, porque as Constituições Fixas foram compreendidas como Rígidas ou Flexíveis, nunca como um tertius genus. Mesmo a classificação das Constituições em Rígidas e Flexíveis não é livre de críticas. De qualquer feita, sendo o discurso sobre a Rigidez, dispensa-se a classificação e as comparações, contenta-se com a categoria Constituição Rígida, por dispor de conteúdo significativo identificável na doutrina.

2.9. O debate da estabilidade das Constituições Rígidas passa obrigatoriamente pela discussão do conceito de Constituição. Para tanto, as obras de Kelsen, Schmitt e Lassale são de utilidade manifesta, porque permitem averiguar a estabilidade em diferentes quadrantes: normativo, político e sociológico.

3. Constituições Rígidas: Limitações ao Poder de Reforma, Mutação Constitucional e Garantias da Constituição.

3.1. A constitucionalização empreendida após a Segunda Guerra Mundial deu-se por meio de Constituições Rígidas. As Constituições Rígidas são compreendidas como aquelas dotadas de um procedimento dificultoso de reforma, quando comparado com o procedimento de alteração da legislação comum.

3.2. A ascensão das Constituições Rígidas não foi um processo retilíneo, homogêneo e predestinado ao sucesso desde o nascedouro. Avanços e retrocessos confluíram em sua formação, como também a experimentação e a produção teórica de tradições distintas: a tradição americana, a tradição européia revolucionária, monárquica, democrática do período entre Guerras e democrática do Pós-guerrra.

3.3. A supremacia constitucional está na abertura, no portal, de qualquer investigação sobre as Constituições Rígidas. A supremacia compreende a supremacia material e a supremacia formal. Em seu sentido material, a supremacia erige-se sobre o seu próprio conteúdo, que lhe confere a primazia de encimar um dado ordenamento. A superioridade formal da Constituição decorre da solenidade de seu procedimento de transformação, quando comparado com o da legislação ordinária. A vinculação entre a supremacia material e formal é estreita. A importância das normas materialmente constitucionais refreia o legislador em sua pretensão de modificá-las, porém, a previsão de um texto escrito e de um procedimento dificultoso tornam isso indiscutível. Enquanto a 
supremacia material confere somente um respeito político, a supremacia formal firma um compromisso dos legisladores a uma obediência jurídica. Mais do que isso, a forma sustenta o conteúdo, e de duas maneiras: pela previsão de um texto escrito e pela existência de um procedimento dificultoso.

3.4. Uma das características das Constituições Rígidas é sua imutabilidade relativa, conceito para o qual convergem idéias antitéticas. De um lado, a concepção de mudança, modificação e adaptação constitucional a uma realidade política, econômica e social cambiante; e de outro lado, a noção de entraves, impedimentos, limites à mesma mudança.

3.5. A modificação nas Constituições Rígidas é empreendida pelo exercício do Poder Reformador - competência constitucional submetida a limites e condições — e pela Mutação Constituição.

3.6. Em regra, a transformação nas Constituições Rígidas é externada pela Mutação Constitucional, haja vista que a atribuição reformadora está submetida aos mais diferentes limites: a) expressos, que se subdividem em procedimentais, temporais, circunstanciais e materiais; b) implícitos. A Reforma e a Mutação Constitucional complementam-se, mas não é raro excluírem-se. Quando uma Constituição é freqüentemente reformada, não há espaço para as mutações constitucionais; mas quando o exercício do Poder Reformador é moderado, a mutação constitucional é o meio por excelência de seu aprimoramento. São mecanismos de mutação constitucional, entre outros: a) a interpretação constitucional, de natureza legislativa, administrativa ou judiciária; b) os costumes constitucionais; c) as convenções constitucionais.

3.7 As Constituições Rígidas são estruturadas em um composto de abertura e obrigatoriedade. Não são completas, fechadas, perfeitas e dispostas em pormenores exaustivos, porque necessitam de espaço para um diálogo sócio-político. Do contrário, esse diálogo seria de mera execução da Constituição, o que se mostraria inaceitável. Não codificam, mas regulam o aspecto político e o sociológico como facetas complementares, espaço que nem sempre é livre de tensão. Por sua vez, a abertura para o diálogo e o aprendizado sociológico não é absoluto, pois os traços principais da ordem político-jurídica devem estar protegidos da luta permanente dos diversos grupos e correntes.

3.8 Não existe uma fórmula ideal e adequada de estabilidade e mobilidade — como uma "receita de bolo" - para toda e qualquer Constituição ou sistema constitucional. Os elementos de abertura e estabilidade são múltiplos, e admitem arranjos dos mais diferentes. Por isso, não há como sugerir de maneira abstrata um modelo padrão, 
que utilizado, permita cotejar as diversas Constituições e do cotejo obter juízos de valor sobre estabilidade ou mobilidade. A investigação deverá ocorrer caso à caso, segundo a disposição de seus vários elementos: normativos, políticos e sociológicos.

3.9 Os instrumentos de garantia da norma constitucional assumem características distintas, conforme a natureza da afronta a ser coibida: atos normativos comissivos ou omissos inconstitucionais e fatos inconstitucionais. Em linhas gerais são identificados como garantias institucionais e "não institucionais". A partir do desenvolvimento do aspecto normativo das Constituições - quando deixaram de ser compreendidas exclusivamente como pactos políticos, para se transformarem em normas sujeitas à aplicação —, os instrumentos institucionais de garantia constitucional tiveram especial progresso e podem ser classificados em: a) garantias para as situações de normalidade constitucional; b) garantias para preservação da Constituição nos momentos de crise.

3.10 Existem sistemas distintos de controle de constitucionalidade e a sua eficácia maior ou menor depende de vários fatores, a começar pelo exercício da fiscalização e sua dupla função: a) negativa, quando suprime a norma ou o ato normativo que desatende os preceitos constitucionais; b) positiva, quando permite a concretização e o desenvolvimento das normas constitucionais. Em regra geral, podem ser elencados: a) o sistema americano de controle de constitucionalidade; b) o sistema kelseniano; c) o sistema preventivo de tipo francês.

3.11 A normalidade e o império do Direito não são perenes. Ocorrem situações excepcionais que fogem aos seus domínios, ditas de crise, para quando as Constituições Rígidas prevêem mecanismos de reabilitação da normalidade.

4. A Organização Constitucional Brasileira Pré-1988: Instabilidade Constitucional

4.1 A Organização Constitucional Brasileira anterior à 1988 é caracterizada por uma instabilidade recorrente. A despeito da estrutura normativa - em princípio eficaz e bastante para preservar sua integridade - as diversas Constituições sucumbiram pelas razões das mais diferentes.

4.2. A fonte de instabilidade da Constituição de 1824 estava na previsão do Poder Moderador, que desequilibrava as relações entre os distintos poderes do Estado.

4.3 A Constituição de 1891 foi uma Constituição nominal porque havia uma incompatibilidade entre a Constituição normativa e a Constituição sociológica, o que a tornou ineficaz e contribuiu para sua ruptura. 
4.4. O período de 1930 à 1945 consistiu em uma época de rara instabilidade, em razão da figura pessoal de Getúlio Vargas, que abertamente conspirava para o exercício exclusivo e pessoal do poder político.

5.5. A Constituição de 1946 sucumbiu porque todas as forças sociais e políticas reagentes, sob a sua vigência, eram golpistas e acabaram por comprometer sua integridade, permitindo o golpe de Estado.

5.6. A práxis sob a égide da Constituição de 1967 e da Emenda constitucional $n^{0}$ 1/69 denota a preponderância desmedida do Executivo, ocupado e apoiado pelas armas, e que vergou a organização constitucional. Essa foi a origem e a raiz da instabilidade política e constitucional. Instabilidade profunda, porque não se limitava a alterar disposições constitucionais de ordem material, como o próprio fundamento de validade da Constituição.

\section{A Constituição de 1988}

5.1 Desde que promulgada, a Constituição de 1988 tem se transformado em ritmo acelerado. Sofreu cinqüenta e seis emendas - segundo o rito previsto em seu artigo 60 - , outras seis de revisão (art. $3^{\circ}$, do ADCT) e, ainda, uma mudança proveniente da incorporação de um tratado internacional, segundo o rito do art. 5 ${ }^{\circ}$, § $3^{\circ}$ da CF/88.

5.2 Parte das razões dessa reformulação constante encontra-se em seu aspecto formal: texto analítico, heterogêneo, de redação imprecisa e excesso de dispositivos concretos sem grandeza para a estatura constitucional. As características formais de seu texto, por sua vez, têm sua gênese no processo constituinte.

5.3 A Constituição de 1988 pode ser classificada como Rígida. O procedimento regulado para sua alteração formal é solene, se comparado com as demais espécies normativas dispostas em seu artigo 59, incisos de II à VII. Os limites ao Poder Reformador não discrepam em grande parte das Constituições que antecederam a de 1988, a fazer crer que a instabilidade tenha causas mais profundas que o mero aspecto formal.

5.4. A Constituição de 1988 é dotada de um complexo sistema de controle de constitucionalidade, resultado da previsão conjunta de elementos do sistema americano e kelseniano. Caminha-se para uma preponderância incontrastável do último modelo, o que contribuirá em efetividade para a garantia da estabilidade constitucional.

5.5. Quando são analisadas as diferentes reformas sofridas pela Constituição de 1988, observa-se que com exceção do Preâmbulo e do Título I, tudo o mais restou modificado, inclusive as disposições constitucionais transitórias. O esforço empreendido não guardou um projeto coerente, sistemático e global. A mudança freqüente produziu-se, 
muitas vezes, por casuísmos ou por necessidades emergenciais do Estado. A maior parte das emendas foi proposta pelo próprio Legislativo. Aquelas apresentadas nos termos do art. 60 da CF/88 estão na proporção de vinte oferecidas pelo Executivo para trinta e seis pelo Legislativo. Esses dados devem ser lidos com alguma reserva: a) o número de emendas do Executivo não é pequeno; b) não é desconhecido que o Executivo disponha de força política para impor seus projetos pela câmara legislativa. O número excessivo de reformas gerou uma instabilidade normativa na aparência, mas não na essência. O núcleo essencial da Constituição restou preservado, a opção política do constituinte indene, pois as emendas não tocaram em profundidade nas regras materialmente constitucionais.

5.6. As mudanças freqüentes da Constituição têm duas causas: a) uma de natureza estrutural; b) outra de fundo ideológico, que se refere ao modelo de Constituição apropriado em 1988. Por causa de natureza estrutural entenda-se um texto analítico, com disposições concretas e sem importância para ocuparem a hierarquia constitucional. Por causas de modelo leia-se a cópia da Constituição Portuguesa, com inspiração na concepção de Constituição Dirigente de Canotilho, o que corresponde a: a) normas programáticas; b) imposições constitucionais de natureza concreta, de cunho gerenciador das políticas públicas.

5.7 A Constituição de 1988 dispõe de uma série de imposições constitucionais particulares vinculativas do legislador. O legislador, por sua vez, não possui outro instrumento para o governo do Estado, que está petrificado no texto da Constituição. Nessa perspectiva, para o exercício da governabilidade, empreendeu as reformas para acomodar a Constituição às contingências econômicas e sociais. Na verdade, a governabilidade e a execução das políticas públicas assumiu hierarquia constitucional sob a vigência da Constituição de 1988.

5.8. As reformas freqüentes abalam o sentimento constitucional. Quando as mudanças são freqüentes, o sentimento suscitado, ainda que irracional, é de descumprimento da Constituição. Sendo violada e não sendo reprimido o ilícito, ou seja, evitadas novas reformas, o sentimento constitucional em princípio justo e propiciador de seu respeito e adesão, transmuta-se em sinal inverso, passando a Constituição a ser desprestigiada. O desprestígio não deixa de ser um desvalor sem conseqüência, uma vez que permite novas reformas em uma crise de auto-referência. Efetivamente, a partir de seu desprestígio e percepção como algo menor, como uma norma banal, não existem entraves à banalização das reformas. 
5.9. Há o perigo real que a banalização das reformas banalize as regras materialmente constitucionais, permitindo que em reformas futuras sejam comprometidas.

5.10. Para solução da instabilidade normativa, sugere-se uma reforma que introduza um duplo procedimento reformador: a) um mais agravado - que poderá ser o atual ou com reforço dos limites — para as regras materialmente constitucionais; b) um menos dificultoso, para as demais matérias, com limites próximos da legislação complementar. 


\section{REFERÊNCIAS BIBLIOGRÁFICAS}

ACKERMAN, Bruce. Nós, o povo soberano: fundamentos do Direito Constitucional. Belo Horizonte: Del Rey, 2006.

. A ascensão do Constitucionalismo Mundial. In: SOUZA NETO, Cláudio Pereira de; SARMENTO, Daniel (Coord.). A Constitucionalização do Direito: Fundamentos Teóricos e Aplicações Específicas. Rio de Janeiro: Editora Lumen Juris, 2007.p.89-111.

AGESTA, Luís Sánchez. Curso de Derecho Constitucional Comparado. $7^{\text {a }}$ ed. Madrid: Facultad de Derecho - Universidad Complutense. 1988.

AMARAL JÚNIOR, José Levi do. Incidente de Argüição de Inconstitucionalidade: comentários ao artigo 97 da Constituição e os arts. 480 a 482 do Código de Processo Civil. São Paulo: RT, 2002.

ARENDT, Hannah. Sobre a Revolução. Lisboa: Relógio D’Água Editores, 2001.

ARISTÓTELES. A política. São Paulo: Editora Tecnoprint, [1990?].

Aulete, F. J. Caldas. Dicionário Contemporâneo da Língua Portuguesa. $2^{\mathrm{a}}$ ed. Lisboa: Parceria Antonio Maria Pereira, 1925. v. 1.

BADIA, Juan Ferrando. Estudios de Ciencia Politica y de Teoria Constitucional. $3^{\text {a }}$ ed. Madri: Editorial Tecnos, 1988.

BARBOSA, Ruy. A Constituição e os Actos Inconstitucionaes do Congresso e do Executivo ante a Justiça Federal. $2^{a}$ ed. Rio de Janeiro: Flores e Mano, sem data.

BARENDT, Eric. An Introduction to Constitutional Law. Oxford: Oxford University Press, 1998.

BARNETT, Hilaire. Constitutional and Administrative Law. $4^{\mathrm{a}}$ ed. London: Cavendish Publishing Limited, 2002.

BARROSO, Luís Roberto. Interpretação e aplicação da Constituição. São Paulo: Saraiva, 1996. 
O Controle de Constitucionalidade no Direito Brasileiro: exposição sistemática da doutrina e análise crítica da jurisprudência. São Paulo: Saraiva, 2004.

Neoconstitucionalismo e Constitucionalização do Direito (O triunfo tardio do direito constitucional no Brasil). In SAMPAIO, José Adércio Leite [Coord.]. Constituição e Crise Política. Belo Horizonte: Del Rey, 2006.p.97-157.

BARRUFINI, José Carlos Toseti. Revolução e Poder Constituinte. São Paulo: RT, 1976.

BARTHÉLEMY, Joseph et DUEZ, Paul. Traité de Droit Constitutionnel. Paris: Librairie Dalloz, 1933.

BASTOS, Celso Ribeiro. Curso de Direito Constitucional. 15 a ed. São Paulo: Saraiva, 1994.

Hermenêutica e Interpretação Constitucional. $2^{\text {a }}$ ed. São Paulo: Celso Bastos Editor, 1999

BASTOS, Celso Ribeiro et MARTINS, Ives Gandra. Comentários à Constituição do Brasil. São Paulo: Saraiva, 1988. v. 1.

BEÇAK, Rubens. A Hipertrofia do Executivo Brasileiro: o impacto da Constituição de 1988. Tese de Doutorado. São Paulo: Universidade de São Paulo, 2005.

BERCOVICI, Gilberto. A Constituição Dirigente e a Crise da Teoria da Constituição. In SOUZA NETO, Cláudio Pereira de et al. Teoria da Constituição: estudos sobre o lugar da política no Direito Constitucional. Rio de Janeiro: Editora Lumen Juris, 2003.p.75-150.

Constituição e Estado de Exceção Permanente - Atualidade de Weimar, Rio de Janeiro: Azougue Editoral, 2004.

Constituição Econômica e Constituição Dirigente. in BONAVIDES, Paulo; LIMA, Francisco Gérson Marques de et BEDÊ, Fayga Silveira [Coord.]. Constituição e Democracia: estudos em homenagem de J. J. Gomes Canotilho. São Paulo: Malheiros, 2006. p. 219-251.

BIGNAMI, Marco. Costituzione Flessibile, Costituzione Rigida e Controllo di Costituzionalità in Italia (1848-1956). Milano: Dott. A. Giuffrè Editore, 1997. 
BITTAR, Eduardo Carlos Bianca et ALMEIDA, Guilherme Assis de. Curso de Filosofia do Direito. $2^{\text {a }}$ ed. São Paulo: Editora Atlas, 2002.

BITTENCOURT, C. A. Lúcio. O Controle da Constitucionalidade das leis. Rio de Janeiro: Forense, 1949.

BOBBIO, Norberto. Teoria Geral da Política: a filosofia política e a lição dos clássicos. Rio de Janeiro: Campus, 2000.

BONAVIDES, Paulo et ANDRADE, Antônio Paes de. História Constitucional do Brasil. Brasília: Centro Gráfico do Senado Federal: 1989.

BONAVIDES, Paulo. Curso de Direito Constitucional. 20a ed. São Paulo: Malheiros, 2007

BORJA, Rodrigo. Derecho político y constitucional. $2^{\circ}$ ed. México: Fondo de Cultura Económica, 1992.

Enciclopédia de la Política. México: Fondo de Cultura Económica, 1998.

BOUTHOUL, Gaston et MOSCA, Gaetano. História das Doutrinas Políticas: desde a antiguidade. $3^{\mathrm{a}}$ ed. Rio de Janeiro: Zahar Editores, 1975.

BRASIL. Supremo Tribunal Federal. Ação Declaratória de Constitucionalidade $\mathbf{n}^{\mathbf{0}} \mathbf{1}$, do Tribunal Pleno do Supremo Tribunal Federal. Brasília, DF, de 27 de outubro de 1993. In Revista Trimestral de Jurisprudência, Brasília, ${ }^{\circ}$ 157, p. 371-411.

BRYCE, James. A Comunidade Americana. Rio de Janeiro: Edições o Cruzeiro, 1959. v. 2

Constituciones Flexibles y Constituciones Rígidas. $2^{\mathrm{a}}$ ed. Madrid: Instituto de Estudios Políticos, 1962.

BUENO, José Antônio Pimenta. Direito Público Brasileiro e Análise da Constituição do Império. Brasília: Editora Unb/Senado Federal, 1978.

BURDEAU, Georges. Traité de Science Politique. Paris: Librairie Génerale de Droit e Jurisprudence, 1950. v.3. 
BURDEAU, Georges; HAMON, Francis et TROPER, Michel. Droit Constitutionnel. $26^{a}$ ed. Paris: L G. D. J., 1999.

BURNS, Edward Mcnall; LERNER, Robert E. et MEACHAM, Standisch. História da Civilização Ocidental: do homem das cavernas às naves espaciais. $40^{\mathrm{a}}$ ed. São Paulo: Globo, 2000.

CAGgianO, Mônica Herman. A emergência do Poder Judiciário como contraponto ao bloco monocolor Legislativo Executivo" in MORAES, Alexandre de [Coord.]. Os 20 anos da Constituição da República Federativa do Brasil. São Paulo: Atlas, 2009.p.99123.

CAETANO, Marcelo. Direito Constitucional. Rio de Janeiro: Forense, 1977.

CAMPANHOLE, Hilton Lobo et CAMPANHOLE, Adriano [Cop.]. Constituições do Brasil. 13 ${ }^{a}$ ed. São Paulo: Editora Atlas, 1999.

CAMPOS, Francisco. O Estado Nacional: sua estructura, seu conteúdo ideológico. $3^{\mathrm{a}}$ ed. Rio de Janeiro: Livraria José Olympio Editora, 1941.

CANOTILHO, José Joaquim Gomes. Rever ou Romper com a Constituição Dirigente? Defesa de um Constitucionalismo Moralmente Reflexivo. In. Cadernos de Direito Constitucional e Ciência Política. São Paulo: RT, abril-junho 1996. n.15.p.7-19.

Direito Constitucional e Teoria da Constituição. 6 6 ed. Coimbra: Almedina, 2002.

. Constituição Dirigente e Vinculação do Legislador. $2^{\mathrm{a}}$ ed. Coimbra: Coimbra Editora, 2001.

CAPPELLETTI, Mauro. O controle judicial de constitucionalidade das leis no Direito Comparado. $2^{\mathrm{a}}$ ed. Porto Alegre: Sérgio Antonio Fabris Editor, 1999.

CASTRO, Carlos Roberto de Siqueira. O devido processo legal e a razoabilidade das leis na nova Constituição do Brasil. Rio de Janeiro: Forense, 1989.

CAVALCANTI, João Barbalho Uchoa. Constituição Federal Brasileira: comentários. $2^{a}$ ed. Rio de Janeiro: F. Briguet e Cia. Editores, 1924. 
CHAUÍ, Marilena. Introdução à história da filosofia: dos pré-socráticos a Aristóteles. 2ed. São Paulo: Companhia das Letras, 2002.

CHORÃO, Mário Bigotte. In SOCIEDADE CIENTÍFICA DA UNIVERSIDADE CATÓLICA PORTUGUESA. Polis: enciclopédia verbo da Sociedade e do Estado. $2^{\text {a }}$ ed. Lisboa: Editorial Verbo, [1997]. 5 v. verbete: segurança jurídica

CÍCERO. Da República. Bauru: Edipro, 1995.

CLÉVE, Clèmerson Merlin. A fiscalização abstrata da constitucionalidade no Direito brasileiro. 2a . São Pauulo: RT, 2000.

COOLEY, Thomas M. Princípios Gerais de Direito Constitucional nos Estados Unidos da América. Campinas: Russel, 2002.

COLLIVA, Paolo. in BOBBIO, Norberto; MATTEUCCI, Nicola et PASQUINO, Gianfranco. Dicionário de Política. $4^{a}$ ed. Brasília, DF: Editora Universidade de Brasília, 1992. v. 1. verbete: império.

CONSTANT, Benjamin. Escritos de política. São Paulo: Martins Fontes, 2005.

COPPOLA, Marcelo. Propostas de iniciativa popular aceleram a coleta de assinaturas. Folha de São Paulo, São Paulo, 21/06/1987. p. A-8.

COSTA, Emília Viotti da. O Supremo Tribunal Federal e a construção da cidadania. 2a .São Paulo: Editora Unesp, 2006.

COSTA, José Manuel Cardoso da. in Sociedade Científica da Universidade Católica Portuguesa. Polis: enciclopédia verbo da sociedade e do Estado. $2^{\mathrm{a}}$ ed. Lisboa/São Paulo: Editorial Verbo, 1997. v.1.verbete constitucionalismo.

CRETELLA JÚNIOR, José. Comentários à Constituição de 1988. $3^{\mathrm{a}}$ ed. Rio de Janeiro: Forense Universitária, 1997. v. 1.

CUNHA, Paulo Ferreira da. Teoria da Constituição: mitos, memórias, conceitos. Lisboa/São Paulo: Editorial Verbo, 2002. v. 1.

DÍAS, Elías. Estado de Derecho y Sociedad Democrática. 9ª ed. Madrid: Taurus, 1998. 
DICEY, A. V. Introduction to the study of the Law of the Constitution. $8^{\text {a }}$ ed. London: Macmillan and Co. Limited, 1927.

DINIZ, Maria Helena. Conflito de Normas. São Paulo: Saraiva, 1998.

. Norma Constitucional e seus efeitos. 4a ed. São Paulo: Saraiva, 1998.

Compêndio de Introdução à Ciência do Direito. 15ª ed. São Paulo: Saraiva, 2003.

DROMI, José Roberto. La Reforma Constitucional: el constitucionalismo del 'por venir'. In: El Derecho Público de Finales de Siglo: Uma perspectiva Iberoamericana. Madrid: Fundación BBV, 1997.

DUARTE NETO, José. A Iniciativa popular na Constituição Federal de 1988. São Paulo: RT, 2005.

ENTERRIA, Eduardo Garcia de. La lucha contra las inmunidades del Poder em el derecho administrativo (Poderes discrecionales, poderes de govierno, poderes normativos). $3^{\mathrm{a}}$ ed. Madrid: Editorial Civitas, 1989.

FAORO, Raymundo. Os Donos do Poder: formação do patronato político brasileiro. $10^{a}$ ed. São Paulo: Editora Globo, 2000. v. 1

FAUSTO, BORIS. História do Brasil. 9ª ed. São Paulo: Edusp, 2001.

FAVOREU, Louis. As Cortes Constitucionais. São Paulo: Landy Editora, 2004.

FERRARI, Regina Maria Macedo Nery. Efeitos da Declaração de Inconstitucionalidade. $4^{\mathrm{a}}$ ed. São Paulo: RT, 1999.

FERRAZ, Anna Cândida da Cunha. Processos Informais de Mudança na Constituição. São Paulo: Max Limonad, 1986.

FERREIRA, Francisco Pinto. Princípios Gerais do Direito Constitucional Moderno. $4^{\text {a }}$ ed. São Paulo: Saraiva, 1962. Tomo I. 
FERREIRA FILHO, Manoel Gonçalves. O Estado de Sítio na Constituição Brasileira de 1946 e na sistemática das medidas extraordinárias de defesa da Ordem Constitucional. São Paulo: RT, 1964.

Comentários à Constituição brasileira: Emenda Constitucional $n^{0}$ 1, de 17 de outubro de 1969. $2^{\text {a }}$ ed. São Paulo: Saraiva, 1977. v. 1 e 3.

O Anteprojeto dos Notáveis. São Paulo: Saraiva, 1987.

. Comentários à Constituição Brasileira de 1988. São Paulo: Saraiva, 1990. v. 1.

. O Parlamentarismo. São Paulo: Saraiva, 1993.

. Constituição e Governabilidade: ensaio sobre a (in)governabilidade brasileira. São Paulo: Saraiva, 1995.

. Do Processo Legislativo. $3^{\text {a }}$ ed. São Paulo: Saraiva, 1995.

O Poder Constituinte. $3^{\text {a }}$ ed. São Paulo: Saraiva, 1999.

. Curso de Direito Constitucional. $28^{\text {a }}$ ed. São Paulo: Saraiva, 2002.

Direitos Humanos Fundamentais. 5ª ed. São Paulo: Saraiva, 2002.

Aspectos do Direito Constitucional Contemporâneo. São Paulo: Saraiva, 2003.

Estado de Direito e Constituição. $3^{\mathrm{a}}$ ed. São Paulo: Saraiva, 2004.

FINER, Samuel Edward. Governo Comparado. Brasília: Editora Universidade de Brasília, 1981.

The History of Government: empires, monarchies and the modern state. Oxford: Oxford Press, 2003. v. 1 e 3.

FIORAVANTE, Maurizio. Constitución: de la Antigüedade a nuestros dias. Madrid: Editorial Trotta, 2001. 
FRANCO, Afonso Arinos de Melo. Curso de Direito Constitucional Brasileiro. Rio de Janeiro: Forense, 1960. v. 2.

GARCÍA-PELAYO, Manuel. Derecho Constitucional Comparado. Madrid: Alianza Editorial, 2000.

GARNER, Bryan A. (Editor in Chief). Black's Law Dictionary. $7^{\text {a }}$ ed. St. Paul: West Group: 1999.

GENRO, Tarso. Método e Constituição Dirigente. in MARTINS, Ives Gandra et REZEK, Francisco. Constituição Federal: avanços, contribuições e modificações no processo democrático brasileiro. São Paulo: Saraiva, 2008.p.47-72.

GLOTZ, Gustave. Princípios da Democracia Ateniense, in CARDOSO, Fernando Henrique et MARTINS, Carlos Estevam (orgs.). Política e Sociedade. São Paulo: Editora Nacional, 1983. v.1.

GORENDER, Jacob. Combate nas Trevas. 5ª ed. São Paulo: Editora Ática, 1998.

GUASTINI, Ricardo. La “Constitucionalización” del Ordenamiento Jurídico: el caso italiano. In CARBONELL, Miguel [org.]. Neoconstitucionalismo (s). $2^{\text {a }}$ ed. Madrid: Editorial Trotta, 2005.p.49-73.

GUETZÉVITH, Mirkine B. As novas tendências do Direito Constitucional. São Paulo: Companhia Editora Nacional, 1933.

HAURIOU, Maurice. Princípios de Derecho Público Y Constitucional. Granada: Editorial Comares, 2003.

HELLER, Herman. Teoria do Estado. São Paulo: Editora Mestre Jou, 1968.

Démocratie Politique et Homogénéite Sociale (1928) Revue Cités nº 6. Paris: PUF, abril de 2001. p.199-211.

HESSE, Konrad. A força normativa da Constituição. Porto Alegre: Sérgio Antonio Fabris, 1991. 
Elementos de Direito Constitucional da República Federal da Alemanha. $20^{a}$ ed. Porto Alegre: Sérgio Antonio Fabris Editor, 1998.

HORTA, Raul Machado. Direito Constitucional. 3ª ed. Belo Horizonte: Del Rey, 2002.

HOUAISS, Antônio et VILLAR, Mauro de Salles. Dicionário Houaiss da Língua Portuguesa. Rio de Janeiro: Objetiva, 2001.

JACQUES, Paulino. Curso de Direito Constitucional. 6 $6^{\text {a }}$ ed. Rio de Janeiro: Forense, 1970.

JAQUARIBE, Hélio. Um Estudo Crítico da História. $2^{\text {a }}$ ed. São Paulo: Paz e Terra, 2001. v.1.

JEFFERSON, Thomas. Carta a John Cartwright, 5 de junho de 1824. In Escritos Políticos. São Paulo: Ibrasa, 1964.

JELLINEK, Georg. Reforma Y Mutacion de la Constitucion. Madrid: Centro de Estúdios Constitucionales, 1991

Teoria General del Estado. México: Fondo de Cultura Económica, 2004.

KELSEN, Hans. Teoria Pura do Direito São Paulo: Martins Fontes, 1987.

- Teoria Geral do Direito e do Estado. São Paulo: Martins Fontes; Brasília: Universidade de Brasília, 1990.

. Teoría General del Estado. Granada: Editorial Comares, 2002.

Jurisdição Constitucional. São Paulo: Martins Fontes, 2007.

LAFERRIÈRE, Julien. Manuel de Droit Constitutionnel. $2^{\text {a }}$ ed. Paris: Éditions Domat Montchrstien, 1947.

LASSALLE, Ferdinand. O que é uma Constituição? Campinas: Editora Minelli, 2003. 
LEAL, Roger Stiefelmann. Pluralismo, políticas públicas e a Constituição de 1988: considerações sobre a práxis constitucional brasileira 20 anos depois. In MORAES, Alexandre de [Coord.]. Os 20 anos da Constituição da República Federativa do Brasil. São Paulo: Atlas, 2009.p.73-97

LIPJHART, Arend. Modelos de Democracia: desempenho e padrões de governo em 36 países. Rio de Janeiro: Civilização Brasileira, 2003.

LOCKE, John. Segundo Tratado sobre o Governo Civil. Petrópolis: Editora Vozes, 1994.

LOEWEnSTEIN, Karl. Teoria de la Constitución. 2 2a ed. Barcelona: Editorial Ariel, 1976.

LOPES, Maurício Antônio Ribeiro. Poder Constituinte Reformador: limites e possibilidades da revisão constitucional brasileira. São Paulo: RT, 1993.

MADISON, James, HAMILTON, Alexander et JAY, John. Os artigos Federalistas. Rio de Janeiro: Nova Fronteira, 1993.

MARTINS, António Manuel. In SOCIEDADE CIENTÍFICA DA UNIVERSIDADE CATÓLICA PORTUGUESA. Logos: enciclopédia luso-brasileira de filosofia. Lisboa/São Paulo: Editorial Verbo, 1999. v.3. verbete: João de Salisbúria.p.54.

MARTINS, Ives Gandra da Silva et MENDES, Gilmar Ferreira. Controle Concentrado de Constitucionalidade: Comentários à Lei n. 9.868 de 10-11-1999. São Paulo: Saraiva, 2001.

MARX, Karl et ENGELS, Friedrich. Manifesto do Partido Comunista. 6 a ed. São Paulo: Global Editora, 1987.

MATTEUCCI, Nicola. Organización del Poder y Libertad: historia del constitucionalismo moderno. Madri: Editorial Trotta, 1998.

MACBAIN, Howard Lee. The Living Constitution. New York: The Macmillan Company, 1939.

MAXIMILIANO, Carlos. Comentários à Constituição Brasileira. $5^{\mathrm{a}}$ ed. Rio de Janeiro/São Paulo: Livraria Freitas Bastos, 1955. v. 1. 
MCILWAIN, Charles Howard. Constitucionalismo Antiguo y Moderno. Madrid: Centro de Estudios Constitucionales, 1991.

MEHRING, Franz. Introducción Histórica. In LASSALLE, Ferdinand. ¿Qué es una Constitución? Santa Fe de Bogotá: Editorial Temis, 1997.p.1-33.

MELLO, Oswaldo Aranha Bandeira de. A Theoria das Constituições Rígidas. São Paulo: Empresa Gráfica Revista dos Tribunais, 1934.

MELlO FILHO, José Celso de. Constituição Federal Anotada. 2a ed. São Paulo: Saraiva, 1986.

MENDES, Gilmar Ferreira Mendes. Direitos Fundamentais e controle de constitucionalidade: estudos de direito constitucional. $2^{\mathrm{a}}$ ed. São Paulo: Instituto Brasileiro de Direito Constitucional/Celso Bastos Editor, 1999.

Jurisdição Constitucional: o controle abstrato de normas no Brasil e na Alemanha. $3^{\text {a }}$ ed. São Paulo: Saraiva, 1999.

Moreira Alves e o controle de constitucionalidade no Brasil. São Paulo: Celso Bastos Editor/Instituto Brasileiro de Direito Constitucional: 2000.

Argüição de Descumprimento de Preceito Fundamental: comentários à Lei n. 9.882 de 3-12-1999. São Paulo: Saraiva, 2007.

MENDES, Gilmar Ferreira, COELHO, Inocêncio Mártires et BRANCO, Paulo Gustavo Gonet. Curso de Direito Constitucional. 2a ed. São Paulo: Saraiva, 2008.

MICHILES, Carlos et al. Cidadão Constituinte: a saga das Emendas Populares. Rio de Janeiro: Paz e Terra, 1989.

MIRANDA, Francisco Cavalcanti Pontes. Comentários à Constituição de 1946. $2^{\mathrm{a}}$ ed. São Paulo: Max Limonad, 1953. v. 1

Comentários à Constituição de 1967: com a Emenda n. 1 de 1969. $3^{\mathrm{a}}$ ed. Rio de Janeiro: Forense, 1987. v.1. 
MIRANDA, Jorge. Contributo para uma teoria da inconstitucionalidade. Coimbra: Coimbra Editora, 1996.

Manual de Direito Constitucional: preliminares, o Estado e os Sistemas Constitucionais. $6^{\text {a }}$ ed. Coimbra: Coimbra Editora, 1997.v.1

Manual de Direito Constitucional: constituição e inconstitucionalidade. $3^{\mathrm{a}}$ ed. Coimbra: Coimbra Editora, 1996. v. 2.

MIRANDA, Jorge et MEDEIROS, Rui. Constituição Portuguesa anotada. Coimbra: Coimbra Editora, 2007. v.3.

MORAES, Alexandre de. Jurisdição Constitucional e Tribunais Constitucionais: garantia suprema da Constituição. São Paulo: Atlas, 2000

Direito Constitucional. 21ª . São Paulo: Atlas, 2007.

MORAIS, Carlos Blanco de. Justiça Constitucional: garantia da Constituição e controlo da constitucionalidade. $2^{\text {a }}$ ed. Coimbra: Coimbra Editora, 2006.

MORLINO, Leonardo. in BOBBIO, Norberto; MATTEUCCI, Nicola et PASQUINO, GIANFRANCO. Dicionário de Política. $4^{\mathrm{a}}$ ed. Brasília, DF: Editora Universidade de Brasília, 1992. verbete estabilidade política. p.394-401.

NOVA ENCICLOPÉDIA BARSA. 6a ed. São Paulo: Barsa Planeta Internacional Ltda., 2002. v.11.

ORLANDO, V. E. Principes de Droit Public et Constitutionel. Paris: Ancienne Librairie Thorin et fils, 1902.

OTTO, Ignacio de. Derecho Constituiconal: sistema de Fuentes. $2^{\mathrm{a}}$ ed. Barcelona: Ariel Derecho, 1989.

PACE, Alessandro. La "Natural, Rigidez de las Constituciones Escritas. In PACE, Alessandro et VARELA, Joaquín. La rigidez de las constituciones escritas. Madrid: Centro de Estudios Constitucionales, 1995.p.19-80. 
PASQUINO, Gianfranco. in BOBBIO, Norberto; MATTEUCCI, Nicola et PASQUINO, GIANFRANCO. Dicionário de Política. $4^{\mathrm{a}}$ ed. Brasília, DF: Editora Universidade de Brasília, 1992. verbete revolução.

PIMENTA, José Carlos. A Rigidez constitucional desafiada - Reforma ou Reformismo. in SAMPAIO, José Adércio Leite [Coord.]. Crise e Desafios da Constituição. Belo Horizonte: Del Rey, 2004. 137-146.

PLATÃO. Político. São Paulo: Abril Cultural, 1979.

. As Leis. Bauru: Edipro, 1999.

A República. São Paulo: Edipro, 2001.

PLUTARCO. Vidas. São Paulo: Cultrix, s.d.

POLÍBIOS. História. 2a ed. Brasília: Editora Universidade de Brasília, 1996.

PRADO, Ney. A Constituição de 1988: alguns equívocos de origem. in MARTINS, Ives Gandra et REZEK, Francisco. Constituição Federal: avanços, contribuições e modificações no processo democrático brasileiro. São Paulo: Saraiva, 2008.p.34-46.

RAMOS, Elival da Silva. A Inconstitucionalidade das leis: vício e sanção. São Paulo: Saraiva, 1994.

- A proteção aos direitos adquiridos no direito constitucional brasileiro. São Paulo: Saraiva, 2003.

Perspectivas de Evolução do Controle de Constitucionalidade no Brasil. 2005. 466 p. Tese (Concurso de Titularidade para o Provimento de Cargo de Professor Titular Departamento do Estado - Área de Direito Constitucional). USP. São Paulo.

ROCHA, Cármen Lúcia Antunes. Reforma total da Constituição: remédio ou suicídio constituição? in SAMPAIO, José Adércio Leite [Coord.]. Crise e Desafios da Constituição. Belo Horizonte: Del Rey, 2004.p.147-174.

ROMANO, Santi. Princípios de Direito Constitucional Geral. São Paulo: RT, 1977. 
ROYO, Javier Pérez. La reforma de la Constitucion. Madrid: Publicaciones de Congreso de los Diputados, 1987.

RUFFIA, Paolo Biscaretti Di. Instroducción al derecho constitucional comparado. México: Fondo de Cultura Econômica, 1979. 1984.

Direito Constitucional: instituições de direito público. 9a ed. São Paulo: RT,

SALDANHA, Nelson. O Poder Constituinte. São Paulo: RT, 1986.

. Formação da Teoria Constitucional. 2 ${ }^{\text {a }}$ ed. Rio de Janeiro: Renovar, 2000.

SAMPAIO, José Adércio Leite. Introdução e Bricolagem sobre a Constituição e Crise Política. In SAMPAIO, José Adércio Leite [Coord.]. Crise e Desafios da Constituição. Belo Horizonte: Del Rey, 2004.p.9-29.

SAMPAIO, Nelson de Sousa. O Poder de Reforma Constitucional. $3^{\text {a }}$ ed. Belo Horizonte: Nova Alvorada Edições Ltda., 1994.

SANTOS, Wanderley Guilherme dos. O Cálculo do Conflito: estabilidade e crise na política brasileira. Belo Horizonte: Editora UFMG/Rio de Janeiro: IUPERJ, 2003.

SARMENTO, Daniel. Apontamentos sobre a Argüição de descumprimento de Preceito Fundamental. in TAVARES, André Ramos et. ROTHENBURG, Walter Claudius (org.). Argüição de Descumprimento de Preceito Fundamental: análises à luz da lei $\mathbf{n}^{\circ}$ 9.982/99. São Paulo: Atlas, 2001.p.85-108.

SOUZA JÚNIOR, Cezar Saldanha. O Tribunal Constitucional como poder: uma nova teoria da divisão dos poderes. São Paulo: Memória Jurídica Editora, 2002.

SCHMITT, Carl. Teoría de la Constitución. Madrid: Editorial Revista de Derecho Privado, [s.d]

La defensa de La Constitución. $2^{\text {a }}$ Ed. Madrid: Editorial Tecnos, 1998.

SCHWARTZ, Bernard. Direito Constitucional Americano. Rio de Janeiro: Forense, 1966. 
A History of the Supreme Court. New York: Oxford University Press, 1993.

SÉROUSSI, Roland. Introdução ao Direito Inglês e Norte-americano. São Paulo: Landy Editora, 2001.

SIEYÈS, Emamanuel Joseph. Opinión de Sieyès sobre las atribuciones y la organización de la “Jury Constitutionnaire” propuesta el 2 del Termidor. In MÓRAN, David Pantoja [org. e compilação]. Escritos políticos de Sieyès. México: Fondo de Cultura Económica, 1993.p.257-272.

- A Constituinte Burguesa - Qu'est-ce que le Tiers État? 4 ed. Rio de Janeiro: Editora Lúmen Júris, 2001.

SILVA, Gustavo Justa da Costa e. Os limites da reforma constitucional. Rio de Janeiro: Renovar, 2000.

SILVA, José Afonso da. Curso de Direito Constitucional Positivo. $16^{a}$ ed. São Paulo: Malheiros, 1999.

- Poder Constituinte e Poder Popular: estudos sobre a Constituição. São Paulo: Malheiros, 2002.

SILVA NETO, Francisco da Cunha e et IORIO FILHO, Rafael M. A nova tríade constitucional de Erhard Denninger. In DUARTE, Fernanda et VIERA, José Ribas [org.]. Teoria da Mudança Constitucional: sua trajetória nos Estados Unidos e na Europa. Rio de Janeiro: Renovar, 2005.p1-154.

STRONG, C. F. Modern Political Constitutions. $3^{\text {a }}$ ed. Londres: Sidgwick \& Jackson Limited, 1949.

TAVARES, Ana Lúcia de Lyra. A Constituição de 1988: subsídios para os comparatistas. Revista de Informação Legislativa, ano 28, $\mathrm{n}^{0}$ 109, p. 71-108, jan/mar 1991. 71-108.

TAVARES, André Ramos. Tratado da argüição de preceito fundamental: lei n. 9.868/99 e 9.882/99. São Paulo: Saraiva, 2001.

TEIXEIRA, José Horácio Meirelles. Curso de Direito Constitucional. Rio de Janeiro: Forense Universitária, 1991 
TRIBE, Laurence H. American Constitutional Law. $3^{\circ}$ ed. New York: Foundation Press, 2000.

TOCQUEVILle, Alexis de. A Democracia na América. São Paulo:Martins Fontes, 2001. v. 1. nota L.

VARELA, Joaquín. En defensa de la "Natural” Rigidez de las Constituciones. In PACE, Alessandro et VARELA, Joaquín. La rigidez de las constituciones escritas. Madrid: Centro de Estudios Constitucionales, 1995.p.116-129.

VALENZUELA, Francisco Berlin. Derecho Parlamentario. México: Fondo de Cultura Econômica, 2003.

VANOSSI, Jorge Reinaldo A. Teoría Constitucional. Teoria Constituyente. Poder Constituyente: fundacional; revolucionário; reformador. Buenos Aires: Ediciones Depalma, 1975. v. 1

VEGA, Pedro de. La Reforma Constitucional y la problematica del Poder Constituyente. Madrid: Tecnos, 2007.

VELOSO, Zeno. Controle jurisdicional de constitucionalidade: atualizado conforme as Leis 9868 de 10/11/1999 E 9.882 de 03/12/1999. 2ª ed. Belo Horizonte: Del Rey, 2000.

VERDU, Pablo Lucas. La repercusion de los cambios sociales em las Constituciones Rigidas. In Rev. Internacional de Sociologia. $n^{0}$ 57. [s.d.].

O Sentimento Constitucional: aproximação ao estudo do sentir constitucional como modo de integração política. Rio de Janeiro: Forense, 2006.

VIANNA, Francisco José de Oliveira. O ocaso do Império. $3^{\text {a }}$ ed. Rio de Janeiro: Livraria José Oympio Editora, 1959.

Instituições Políticas Brasileiras: fundamentos sociais do Estado (Direito Público e Cultura). $3^{\mathrm{a}}$ ed. Rio de Janeiro: Record, 1974. v.1.

VIEIRA, Oscar Vilhena. A Constituição e sua reserva de Justiça: um ensaio sobre os limites materiais ao poder de reforma. São Paulo: Malheiros Editores, 1999. 
VILLEY, Michel. In CHÂTELET, François; DUHAMEL, Olivier et PISIER, Evelyne [coord]. Dicionário de Obras Políticas. Rio de Janeiro: Editora Civilização Brasileira, 1993. verbete Tomás de Aquino.

WEBER, Max. Economia e Sociedade. Brasília, DF: Editora Universidade de Brasília, São Paulo: Imprensa Oficial de São Paulo, 1999. v. 2.

WHEARE, K. C. Modern Constitutions. Oxford: Oxford University Press, 1978.

Textos da Internet:

ALEMANHA. Juristiches Internet Projeckt Saarbrücken. Grundgesetz für die Bundesrepublik Deutschland. Disponível em: $<$ http://archiv.jura.unisaarland.de/BIJUS/grundgesetz/Tableau.htm>. Acesso em: 01 dez 2008, às 17:36h.

BARROSO, Luis Roberto. A Constituição não é um empecilho para o desenvolvimento do país. In Revista Época. Debates. 13/09/2008. Rio de Janeiro: Editora Globo, 2008. Disponívelem:<http://editora.globo.com/especiais/2008/Debate/webapp/public_html/debat e_popDebatedor.asp?debate_id=10\&debatedor_id=18\#ancoraAbertura $>$. Acesso em: 19/01/2009, às 00:05 h.

BRASIL. Senado Federal. S!CON: Sistema de Informações do Congresso Nacional. Disponível em: <.http://www6.senado.gov.br/sicon/PreparaPesquisa.action>. Acesso em: 10 nov. 2008.

BRASIL. Supremo Tribunal Federal. Disponível em: $<$ http://www.stf.jus.br/portal/jurisprudencia/listarJurisprudencia.asp>. Acesso em 29 nov. 2008. às 21:39h

BRACTON, Henry . De Legibus et Consuetudinibus Angliae. V. 2. in Bracton on line homepage. Harvard Law School Library. p.2. Disponível em: $<$ http://hlsl5.law.harvard.edu/bracton/Framed/mframe.htm> Acesso em 04/10/2008, às 18:38h.

ESPANHA. Senado de España. Constitución Española. Disponível em:<http://www.senado.es/constitu/index.html>. Acesso em 01 dez 2008, às 18:03 h.

ESTADOS UNIDOS. Cornell University Law School. United States Constitution. Disponível<http://www.law.cornell.edu/constitution/constitution.table.html\#amendments>. Acesso em:01 dez 2008, às 21:22h. 
FRANÇA. Conseil Constitutionnel. La Constitution du 4 Octobre 1958. Disponível em: < http://www.conseil-constitutionnel.fr/conseil-constitutionnel/francais/la-constitution/laconstitution-du-4-octobre-1958/les-revisions-constitutionnelles.5075.html >. Acesso em 01 dez. 2008, às 17:51.

GUILFOY, Kevin. John of Salisbury. in ZALTA, Edward N [ed.]. The Stanford Encyclopedia of Philosophy. Disponível em: $<$ http://plato.stanford.edu/archives/fall2005/entries/john-salisbury/>. Acesso em 26/12/05 às $17: 05 \mathrm{~h}$.

ITÁLIA. Camera dei Deputadi. Piattaforma didattica sulla Costituzione italiana. Disponível em:< http://www.camera.it/eventicostituzione2007/testo/140/schedabase.html> Acesso em: $01 \mathrm{dez}$. 2008, às 17:26 h

JOHN OF SALISBURY. Policraticus. Chapter I. Livro IV. in New York. Internet Medieval Sourcebook. Fordham University: The Jesuit University of New York. Disponível em: <http://www.fordham.edu/halsall/source/salisbury-poli4.html>. Acesso em 14/12/2005, às 18:51.

PORTUGAL. Portal do Governo. Constituição da República Portuguesa. Disponível em: $<$ http://www.portugal.gov.pt/Portal/PT/Portugal/Sistema_Politico/Constituicao/06Revi sao/>.Acesso em 1 dez. 2008, às 17:32h.

ROBBINS, Keith. History and Politics: The Career of James Bryce. In Journal of Contemporary History. Sage Publications Ltd: Julho-Outubro de 1972. V. 7, n. 3/4. pp. 3752. Disponível em < http://www.jstor.org/stable/259904>. Capturado em: 22/04/2008 18:09. 